\title{
Plasma 11-Hydroxycorticoid Levels after Carbenoxolone Sodium
}

\author{
D. MATTINGLY,* M.B., F.R.C.P. ; CHRISTINE TYLER, $\dagger$ B.SC., PH.D. ; ELAINE BILTON, $\ddagger$ A.I.M.L.T.
}

Ummary: A definite rise in plasma 11-hydroxycorti$\checkmark$ coid levels has been shown in eight patients with duodenal ulcer following the oral administration of carbenoxolone sodium. A similar rise was seen in one patient with sarcoidosis whose pituitary A.C.T.H. secretion had been acutely suppressed with dexamethasone. No such rise, however, was seen in three patients suffering from adrenal insufficiency. It is suggested that carbenoxolone acts directly on the adrenal cortex, causing an increased production of corticosteroids.

\section{Introduction}

Carbenoxolone sodium (Biogastrone) is synthesized from glycyrrhizic acid, which is one of the many constituents of liquorice root. Apart from its apparent healing effect on the gastric mucosa, this compound, like crude liquorice preparations, has other pharmacological actions which resemble those of certain adrenocortical hormones. In rats it has an anti-inflammatory action which is about one-third that of cortisol (hydrocortisone) when given by subcutaneous injection, though, unlike cortisol, it is ineffective in rats when given by mouth. This effect persists in hypophysectomized animals but is greatly reduced when both adrenal glands are removed (Khan and Sullivan, 1968).

This anti-inflammatory action of carbenoxolone has not been investigated in man, but a significant proportion of patients treated with this drug have developed salt retention, a rise in blood pressure, hypokalaemia, and occasionally severe potassium depletion (Doll et al., 1962; Doll et al., 1965; Horwich and Galloway, 1965; Turpie and Thomson, 1965; Hausmann and Tarnoky, 1966; Mohamed et al., 1966; Forshaw, 1969). These side-effects have also been reported with crude liquorice preparations, and resemble those produced by an excess of adrenal mineralocorticoids such as is seen in Conn's syndrome.

Possibly these pharmacological actions of carbenoxolone are due to direct stimulation of corticosteroid production by the adrenal cortex, but evidence to support this hypothesis is lacking. In particular, a number of workers have shown that aldosterone secretion is normal or reduced in patients given liquorice or its derivatives (Baron et al., 1969). It has, therefore, been suggested that these results are consistent only with the hypothesis that the mineralocorticoid effect of carbenoxolone is due to its possessing intrinsic aldosterone-like properties. This theory, however, fails to take into account the observations of Borst et al. (1953), who concluded that the favourable effects of liquorice on salt loss in Addison's disease were seen only in those patients who still had some functioning adrenal tissue left, and those of Elmadjian et al. (1956), who found that the mineralocorticoid-like action of monoammonium glycyrrhizinate, observed in intact subjects, was absent in two adrenalectomized patients. The work reported here provides evidence that the administration by mouth of carbenoxolone sodium produces a rise in the unconjugated plasma 11-hydroxycorticoid levels, raising once again the question of its mode of action.

* Director.

t Research Assistant.

$\ddagger$ Research Technician.

Postgraduate Medical Institute, University of Ereter.

\section{Methods}

All the tests were carried out in the morning, and a single dose of $100 \mathrm{mg}$. of carbenoxolone sodium was given orally to the subjects between 10.30 and 11.30, with the exception of one man who was given only $50 \mathrm{mg}$. The tablets were given with $20-30 \mathrm{ml}$. of water. Patients had breakfasted normally at 7.30. Venous blood samples of $5-6 \mathrm{ml}$. were taken from the antecubital fossa by means of an indwelling cannula. Two control samples were taken at intervals of one hour before the dose of carbenoxolone, and further samples were taken over the subsequent two and a half hours.

Plasma 11-hydroxycorticoids (11-OHCS) were estimated by the fluorimetric method previously described, $2 \mathrm{ml}$. of plasma being used for each estimation (Mattingly, 1962). The presence of carbenoxolone sodium in the plasma in concentrations up to $10 \mathrm{mg} . / 100 \mathrm{ml}$. does not interfere with the measurement of 11-OHCS by this technique. The synthetic analogues of cortisol do not fluoresce if this method is used, so that endogenous corticosteroid production can be studied during the administration of these compounds.

\section{Subjects}

The subjects, six men and six women, were all inpatients at the time of study and were resting in bed throughour its duration. The nature and purpose of the investigation was explained to each patient before inclusion in the series. Their ages ranged from 25 to 62 years, and in all but four instances they were suffering from duodenal ulcers. The four exceptions are described below.

Case 1.-A woman of 43 had Addison's disease. On admission her morning plasma 11-OHCS level was only $3.9 \mu \mathrm{g} . / 100 \mathrm{ml}$., and there was no rise in plasma or urinary corticosteroid levels when she was given $1 \mathrm{mg}$. of intramuscular tetracosactrin depot each morning for three days. During this period she was also given prednisolone $2.5 \mathrm{mg}$. and fludrocortisone $0.2 \mathrm{mg}$. daily by mouth, and next day she was again given these steroids five hours before the carbenoxolone was administered.

Case 2.-A man of 58 with a pituitary tumour, was found to have had hypopituitarism two years ago. His morning plasma 11OHCS level was only $0.4 \mu \mathrm{g} . / 100 \mathrm{ml}$., and he had a negligible adrenal response to exogenous A.C.T.H. Since that time he had been maintained on oral cortisol and thyroxine, and on the day of the test was given a single dose of $\mathbf{3 0} \mathrm{mg}$. of cortisol by mouth five and a half hours before the carbenoxolone was administered.

Case 3.-A man of 57 had Addison's disease. His initial morning plasma 11-OHCS level was $8 \mu \mathrm{g} . / 100 \mathrm{ml}$., which is just within the normal morning range, but there was no rise in plasma or urinary steroid levels after three days on tetracosactrin depot in a dose of $1 \mathrm{mg}$. intramuscularly each morning. During the tests he was maintained on oral prednisolone $5 \mathrm{mg}$. twice daily and fludrocortisone $0.1 \mathrm{mg}$. by mouth daily.

Case 4.-A woman of 48 with sarcoidosis, was about to be started on corticosteroid therapy. She was given $2 \mathrm{mg}$. of dexamethasone by mouth at 11.30 on the night before the administration of carbenoxolone, and a further oral dose of $2 \mathrm{mg}$. at 6 a.m. next day in order to ensure acute suppression of pituitary A.C.T.H. secretion during the test. 


\section{Results}

In all the subjects with duodenal ulcers the administration of a dose of carbenoxolone sodium by mouth resulted in a rise in plasma 11-OHCS levels which lasted for between one and one and a half hours. The time at which the maximum response was seen varied from 20 to 60 minutes after the drug had been given. In one of the female patients the test was repeated after she had been treated with carbenoxolone for one week, with similar results. The responses of the four female subjects to $100 \mathrm{mg}$. of carbenoxolone are illustrated in Fig. 1, and the responses of the three male subjects to the same dose are shown in Fig. 2. The response to $50 \mathrm{mg}$. of carbenoxolone is included here for comparison, indicating that the rise is similar but of shorter duration than with the bigger dose. The basal plasma 11-OHCS levels in these patients were all within the normal morning range of 6 to 24 $\mu \mathrm{g} . / 100 \mathrm{ml}$., and the mean rise was $11.9 \mu \mathrm{g} . / 100 \mathrm{ml}$. In women it ranged from 8.4 to $18.0 \mu \mathrm{g} . / 100 \mathrm{ml}$., with a mean of $12.0 \mu \mathrm{g}$./ $100 \mathrm{ml}$., and in males it ranged from 11.4 to $12.0 \mu \mathrm{g} . / 100 \mathrm{ml}$., with a mean of $11.7 \mu \mathrm{g} . / 100 \mathrm{ml}$.

The lack of response to carbenoxolone sodium in patients with Addison's disease and secondary adrenal atrophy is also shown in Figs. 1 and 2. All three patients were receiving corticosteroid maintenance therapy at the time of the test, and the basal plasma 11-OHCS levels were below those of the normal subjects. In none of these three patients was there a significant rise in plasma 11-OHCS levels after the ingestion of $100 \mathrm{mg}$. of carbenoxolone.

The results in Case 4 are shown in Fig. 3. This patient had intact adrenal glands, but pituitary A.C.T.H. secretion had been acutely suppressed by the previous administration of dexamethasone. As expected her basal plasma 11-OHCS levels were below the normal range for this time of day, indicating that suppression had occurred. Nevertheless, she had a good response to carbenoxolone, the level 15 minutes after its administration rising to $19.5 \mu \mathrm{g} . / 100 \mathrm{ml}$. The rapidity of this response can be explained by the fact that carbenoxolone is absorbed from the stomach and the speed of absorption varies from subject to subject.

\section{Discussion}

We have shown that carbenoxolone sodium given by mouth produced a transient but significant rise in plasma 11OHCS levels in nine patients with intact adrenal glands. Carbenoxolone, when added to plasma in concentrations far exceeding those found after such oral doses, did not cause any fluorescence, but possibly the rise in fluorescence might be due to metabolites of this drug. Since no rise was seen in the three patients with adrenal insufficiency, however, this seems unlikely and strongly suggests that this drug has a stimulatory effect on the adrenal cortex. Whether this is due to a direct action on the adrenal glands or to stimulation of pituitary A.C.T.H. secretion cannot be determined from these experiments, though the response of Case 4, whose pituitary A.C.T.H. secretion had been acutely suppressed by dexamethasone, makes it more likely that it is due to a direct action on the adrenal cortex. This conclusion is supported by the studies of Khan and Sullivan (1968), who found that the anti-inflammatory action of carbenoxolone in rats was greatly reduced by bilateral adrenalectomy but not by hypophysectomy.

The analytical method used here measures the total unconjugated 11-hydroxycorticoids in the plasma, and a change of concentration of this magnitude could occur only as a result of either increased production or reduction in the rate of removal from the blood stream. Carbenoxolone is conjugated with glucuronic acid in the liver, and one possible way in which this drug might affect normal adrenal function is by the inhibition of steroid inactivation in the liver, which has been shown to occur in vitro (Atherden, 1958). If this were so, the half-life of cortisol and other steroids in the circulation would be prolonged and might result in a transitory rise in plasma levels. This seems unlikely, however, since in one hypoadrenal patient (Case 2) who was given $30 \mathrm{mg}$. of oral cortisol before the test no such rise was seen.

These results throw no further light on the role of the adrenal cortex in producing the mineralocorticoid-like effects that have been reported with this drug. The rise in plasma 11-OHCS levels reported here cannot be due to an increased output of aldosterone or 11-deoxycorticosterone, since these steroids are not measured by this technique. Baron and his colleagues (1969) reported that the aldosterone secretion rate was reduced in the one patient whom they studied, but we are not aware of any work on the secretion rate of 11-deoxycorticosterone in this situation, and our findings do not exclude the possibility that there is an abnormal production of this or some other steroid with a mineralocorticoid action.

It must be emphasized that this fluorimetric technique measures a number of steroids with similar structure, including cortisol, corticosterone, $20 \beta$-hydroxycortisol and 21-deoxycortisol. Though cortisol is the main 11-hydroxycorticoid in normal human plasma, it cannot be assumed that the rise which we have demonstrated is necessarily due to this steroid.

We are indebted to Dr. S. Gottfried of Biorex Laboratories for a sample of carbenoxolone sodium, to Professor D. V. Parke for useful criticisms, and to Drs. A. J. Edge, J. W. Scott, and Doreen
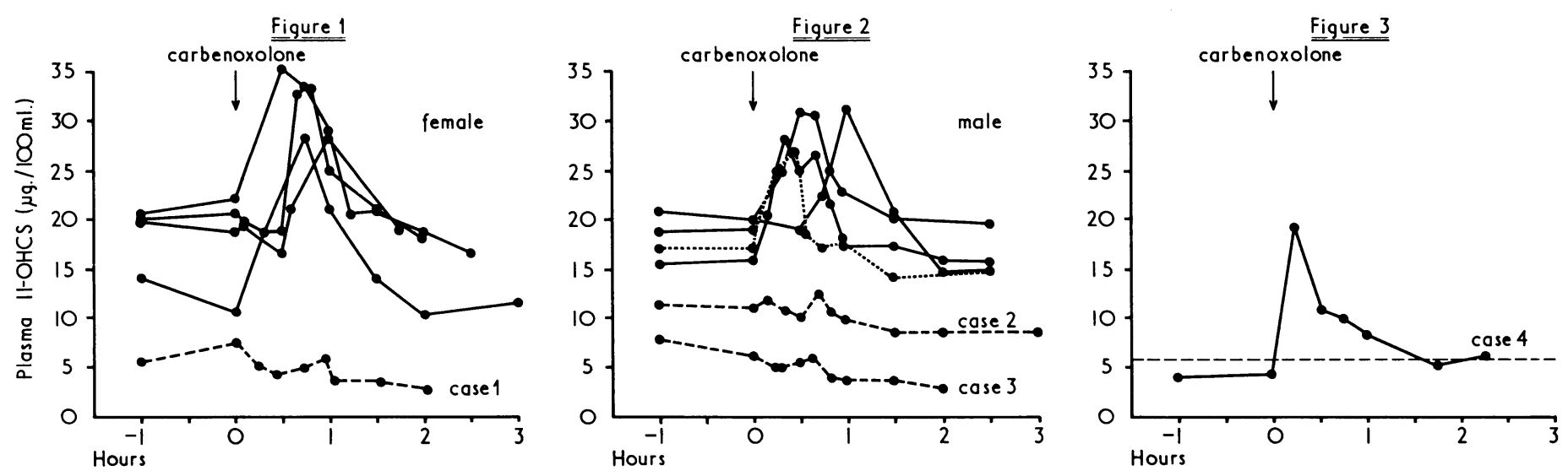

Fig 1.-Response of plasma 11-OHCS to $100 \mathrm{mg}$. of carbenoxolone by mouth in female patients.

Patient with Addison's disease. FIG 2.-Response of plasma 11-OHCS to carbenoxolone patients. $-->=$ ulcers given $100 \mathrm{mg}$. . ........ Patient with duodenal ulcer given $50 \mathrm{mg}$. Response of plasma 11-OHCS to 100 mg. of carbenoxolone by mouth in female patient with sarcoidosis (Case 4). Pituitary A.C.T.H. secretion had been acutely suppressed with dexamethasone. Horizontal dashed line indicates lower limit of normal morning range. 
Keillar for help in taking blood samples. We should also like to thank the Medical Research Council, the Northcott Devon Medical Foundation, and the South Western Regional Hospital Board for financial support.

\section{REFERENCES}

Atherden, L. M. (1958). Biochemical fournal, 69, 75.

Baron, J. H., Nabarro, J. D. N., Slater, J. D. H., and Tuffley, R. (1969). British Medical fournal, 2, 793.

Borst, J. G. G., de Vries, L. A., ten Holt, S. P., and Molhuysen, J. A. (1953). Lancet, 1, 657.

Doll, R., Hill, I. D., and Hutton, C. F. (1965). Gut, 6, 19.
Doll, R., Hill, I. D., Hutton, C. F., and Underwood, D. J. (1962). Lancet, $2,793$.

Elmadjian, F., Hope, J. M., and Pincus, G. (1956). Fournal of Clinical Endocrinology and Metabolism, 16, 338.

Forshaw, J. (1969). British Medical fournal, 2, 674.

Hausmann, W., and Tarnoky, A. L. (1966). British fournal of Pharmacology and Chemotherapy, 26, 412 .

Horwich, L., and Galloway, R. (1965). British Medical fournal, 2, 1274.

Khan, M. H., and Sullivan, F. M. (1968). In Symposium on Carbenoxolone Sodium, ed. J. M. Robson and F. M. Sullivan, p. 5. London, Butterworths.

Mattingly, D. (1962). Fournal of Clinical Pathology, 15, 374.

Mohamed, S. D., Chapman, R. S., and Crooks, J. (1966). British Medical Fournal, 1, 1581.

Turpie, A. G. G., and Thomson, T. J. (1965). Gut, 6, 591.

\title{
Human Fascioliasis in Shropshire
}

\author{
W. L. G. ASHTON, ${ }^{*}$ B.v.sc., M.R.C.v.s. ; P. L $\$ BOARDMAN, $†$ M.D., M.R.C.P. ; C. J. D’SA, $\ddagger$ M.R.C.P. \\ P. H. EVERALL, $\$ F.I.M.L.T. ; A. W. J. HOUGHTON,\| M.R.C.P.
}

Cummary: Five patients with fascioliasis presented with malaise, pruritus, and pain in the right hypochondrium. Eosinophilia, increase in serum gamma globulin, and pyrexia were other features. Four patients treated with oral bithionol recovered completely and it is suggested that this is an effective form of therapy. The double diffusion precipitin test, being speedy and simple, was used as a screening procedure for diagnosis. The source of infection was wild watercress growing in a farm ditch.

\section{Introduction}

The aim of this paper is to describe an outbreak of fascioliasis in humans during which we assessed the response to bithionol (Actamer) and used the double diffusion precipitin reaction as a screening test.

\section{Clinical Description}

\section{The Outbreak}

Case 1.-A housewife aged 22 years was admitted to hospital on 20 December 1968. She complained of attacks of severe pain in the right hypochondrium for three months, loss of appetite, rigors, and weight loss. She had a fever of $39.4^{\circ} \mathrm{C}$. and an enlarged tender liver. Her haemoglobin was $11.6 \mathrm{~g} . /$ $100 \mathrm{ml}$. and the total leucocyte count was 12,000/cu.mm., of which 6,480 were eosinophils. The erythrocyte sedimentation rate was $33 \mathrm{~mm}$. in the first hour (Wintrobe), the serum aspartate transaminase was 28 units, and the serum alkaline phosphatase was $28 \mathrm{King}$-Armstrong units $/ 100 \mathrm{ml}$. The serum albumin was $3.4 \mathrm{~g} . / 100 \mathrm{ml}$. and the globulin $4.5 \mathrm{~g} . / 100$ $\mathrm{ml}$; paper electrophoresis revealed an increase of alpha-2 globulin and a diffuse increase of gammaglobulin. The Wassermann cardiolipin reaction was positive, but the Treponema pallidum immobilization test and Reiter protein complement fixation test were negative. A needle liver biopsy demonstrated focal granulomata with small areas of necrosis

\footnotetext{
- Veterinary Investigation Centre, Woodthorne, Wolverhampton.

† Consultant Physician, Royal Salop Infirmary, Shrewsbury.

¥ Medical Registrar, Royal Salop Infirmary, Shrewsbury.

Technical Officer, Royal Salop Infirmary, Shrewsbury.

\| Consultant Physician, Royal Salop Infirmary, Shrewsbury.

I Present address: Queen Elizabeth Hospital, Birmingham.
}

heavily infiltrated by eosinophils. Ova of Fasciola hepatica were found in the stools. The fasciola complement fixation test was positive $1 / 80$. The double diffusion precipitin test was also positive. The hydatid complement fixation test and Casoni skin test were negative.

This patient was a member of an isolated farming community. The other members of the community were examined; there was neither clinical nor laboratory evidence of infection in 10 of these. The remaining four are described below.

Cases 2-5 consisted of two men aged 58 and 49 and two females aged 45 and 14 years. All had pain in the right hypochondrium, malaise, and pruritus, and in three the liver was enlarged and tender. Eosinophilia between 2,880-6,000 per cu.mm. was present in all. Ova were found in the stools of one patient. The complement fixation test was positive between $1 / 20$ and $1 / 80$ in three. The double diffusion test was positive in all.

\section{Treatment and follow-up details}

Case 1.-This patient was treated in hospital with emetine hydrochloride $60 \mathrm{mg}$. daily, the 10-day course being interrupted for 48 hours because of atrial ectopic beats. Within a week there was definite symptomatic improvement and ova were no longer found in the stools. After three months she relapsed with abdominal pain for a few days; her erythrocyte sedimentation rate was 40 $\mathrm{mm}$. in the first hour and the eosinophil count was 1,300 per cu.mm. After eight months she was well and had a normal eosinophil count, but precipitin and complement fixation tests were still positive. The Wassermann reaction was negative and the serum alkaline phosphatase normal.

Case 2.-This man was treated with bithionol, $1 \mathrm{~g}$. three times daily orally on alternate days. A few hours after the first dose he had very severe pain in the right hypochondrium and treatment was stopped. Within 10 days of restarting he was symptomfree and ova were not present in his stools. Severe nausea limited the total dosage to $22.5 \mathrm{~g}$., but he recovered completely in six weeks. After eight months he was well, had a normal eosinophil count, but was positive serologically.

Cases 3-5.-Two received $45 \mathrm{~g}$. of bithionol, but the dose for the girl aged 14 was limited to $22.5 \mathrm{~g}$. All returned to normal health but experienced nausea and vomiting on the drug. The eosinophil counts returned to normal but the serological reactions remained unchanged after eight months. 